\title{
Parasitas intestinais numa populaçào humana da cidade de Nova Olinda do Norte, Amazonas.
}

\author{
Maria José Rebouças Ferraroni (') \\ Marcelo Montoril Filho $\left({ }^{2}\right)$ \\ José João Ferraroni ${ }^{(3)}$
}

\begin{abstract}
Resumo
Foi realizado um estudo parasitológico na cidade de Nova Olinda do Norte, Estado do Amazonas, Brasil, dando ênfase aos resultados encontrados na população humana jovem. Verificou-se que entre os helmintos a maior prevalência foi representada pelo Ascaris lumbricoides com $70,4 \%$ (169 de 240 ) e o protozoário patogênico que mais prevaleceu foi a Giardia lamblia com $28,4 \%$ ( 68 de 240 ). Discute-se os aspectos parasitários assim como a problemática do controle e manejo dessas infecçōes na infância, principalmente na ausência de recursos paramédicos adequados comum nas localidades do interior amazônico.
\end{abstract}

\section{INTRODUÇÃo}

A cidade de Nova Olinda do Norte representa um ambiente ideal para o estudo das parasitoses intestinais humana devido ao baixo paciaão sanitário em que vive a população. Especialmente porque com o novo plano de saúde ora implantado pelo atual secretário certamente implicará numa melhor condição sanitária da cidade, inclusive com o pleno funcionamento do hospital. Os resultados que se pretende obter neste trabalho poderão servir como meios de comparação com estudos posteriores.

Após um estudo geral do aspecto sanitário da cidade de Nova Olinda do Norte (Montoril et al., 1978), resolveu-se fazer uma avaliação minuciosa sobre o assunto, dando ênfase ac grupo etário dos pacientes, enfocando a população humana jovem. Sabe-se que o fator idade exerce relevante importância numa população quando relacionada aos índices parasitários.

$\mathrm{Na}$ prática médica diária, principalmente no interior, verifica-se que a população jovem apresenta um maior índice de infecção. Por outro lado é oportuno lembrar que para o caboclo amazônico (adulto) é quase um insulto faiar em exames de fezes. Desta maneira, quando solicitada da populaçăo, um maior número de exames são realizados na faixa etária jovem.

A população da cidade de Nova Olinda do Norte, como nas regióes em desenvolvimento, apresenta uma população elevada na faixa etária menor de 12 anos.

\section{MATERIAIS E MÉTODOS}

Dos exames realizados na primeira pesquisa foram retirados, ao acaso, 300 , verificando que somente $240(80 \%)$ eram de pacientes residentes na cidade e $60(20 \%)$ em outras localidades, as quais seriam impossível de serem visitadas, pelo menos no momento. Assim sendo foram computados somente os dados da cidade, representando uma comunidade fechada.

$\mathrm{Na}$ coleta do material usou-se um pequeno recipiente (latinha) o qual foi distribuído e solicitado a população que o trouxesse ao hospital após a obtenção da amostra. Os exames foram realizados no laboratório do hospital existente na cidade. Na realização dos exames foi empregado o método de concentraçăo segundo Faust (1939), considerado simples e eficiente tanto para helmintos como protozoários.

A cidade de Nova Olinda do Norte está situada em terra firme a 54 metros acima do nivel do mar com uma latitude de $4^{\circ} 10^{\prime} \mathrm{S}$ e longitude de $59^{\circ} 18^{\prime} \mathrm{O}$, apresentando um clima

(1) - Hospital Infantil "Dr. Fajardo" e Hospital de Moléstias Tropicais de Manaus.

${ }^{(2)}$ - Secretaria de Saúde do Estado do Amazonas, Manaus.

${ }^{(3)}$ - Instituto Nacional de Pesquisas da Amazônia, Manaus e Hospital de Moléstias Tropicais de Manaus. 
quente e úmido com pequena variaçãc anual de temperatura numa média de $26^{\circ} \mathrm{C}$. (Anuário estatístico do Brasil, 1976). Localiza-se a margem direita do rio Madeira, (água branca) que por sua vez é afluente da margem direita do rio Amazonas. Na época da realização da pesquisa (segundo semestre de 1976), contava com uma população de 2871 habitantes, distribuídos em 531 residências na sede do município.

As fontes de renda do município são pouco representativas, resumindo-se em atividades do comércio e empregos nas repartições públicas municipais e estaduais. A agricultura e a pesca tem pouca representação econômica, determinando um baixo poder aquisitivo da população.

\section{RESULTADOS E COMENTÁRIOS}

Em nossos achados o A. lumbricoides prevaleceu entre os helmintos com uma positividade de $70,4 \%$, seguido pelo $T$. trichiurus com $47 \%$, ancilostomídeos com $30,4 \%$, E. vermicularis com $2,4 \%$ e $S$. stercoralis com $1,7 \%$. Entre os protozoários a $E$. coli foi a mais prevalente com $31,8 \%$, seguida pela Giardia lamblia com $28,4 \%$, E. histolytica com $27,3 \%$, E. nana com $11,4 \%$ e C. mesnili com apenas $1,1 \%$.

$\mathrm{Na}$ amostragem geral tivemos uma positividade de $90,4 \%$ (217 de 240 ), sendo $35 \%$ ( 84 de 240) no sexo masculino e $55,4 \%$ (133 de 240) no sexo feminino. Desta maneira $9,6 \%$ (23 de 240) dos exames foram negativos, $5 \%$ (12 de 240) para o sexo masculino e 4,6 (11 de 240) para o sexo feminino. Notou-se uma alta prevalência da giardíase na faixa etária menor de 4 anos. Ogunba (1977) relata que as crianças menores de 5 anos são mais suceptíveis a infecçōes maciças por $G$. lamblia devido apresentarem maior contato com o solo e pelo fato de ser difícil mantê-las estritamente higiênicas nesta faixa etária. As infecções por $E$. histolytica foram significativas no sexo feminino. A ancilostomíase apresentou-se numa taxa de $30,4 \%$, ficando bem próxima daquelas citadas por Costa (1947) no Estado do Pará 37,6\% e em Itacoatiara no Estado do Amazonas 25,4\%. Foi, no entanto, relativamente baixa quando comparada com as taxas encontradas por Azevedo \& Maroja (1956) no Estado do Pará $80,7 \%$.
Pinheiro et al. (1976) encontraram $35,2 \%$ de positividade para o mesmo parasita em dois bairros de Manaus é Causey et al. (1947) relatam uma prevalência de $42,3 \%$ em indivíduos menores de 14 anos na cidade de Belém. Estado do Pará.

Nas localidades onde existem boas condições higiênicas da população a prevalência das infecções por helmintos e protozoários intestinais é extremamente variável, sofrendo influência direta das condiçōes climáticas. No sul dos EUA, próximio a foz do Mississipi o T. trichiurus e encontrado em $56 \%$, A. lumbricoides em $21 \%$ e G. lamblia em $10 \%$ da população humana jovem (Blumenthal \& Schultz, 1976). É difícil de explicar o porquê, certas regiões apresentam indices mais elevados de infecções, mas certamente a prevalência varia com as condiçōes higiênicas e sanitárias da população, assim como, está na dependência do clima, principalmente da umidade relativa do ar atmosférico. As regiões situadas próximas ao trópico são as que melhores condi. ções oferecem à sobrevivência e disseminação dos parasitas.

Tratar corretamente parasitas intestinais em crianças é difícil, pois todas as drogas disponiveis causam efeitos colaterais, principalmente se não forem administradas com muita cautela. Só no Japão os derivados do grupo hidroxiquinoleinas foram responsáveis por mais de 10.000 casos de neuropatia óptica subaguda, sendo atualmente proibido o uso da droga naquele país. Na Suécia e Austrália esta síndrome também é muito freqüente. Os derivados deste fármaco, por serem de fácil acesso e de baixo custo, são usados em grande escala pela população do interior, para tratar diarréias de quaisquer etiologia.

Desde 1964 o thiabendazol representa um dos mais potentes antilhelmíntico de largo espectro, no entanto, efeitos colaterais são rela. tados constantemente não só no trato intestinal como também no sistema nervoso central. Reações alérgicas incluindo anafilaxia e síndrome de Stevens Johnson já foram relatadas.

Os derivados nitrofurantoínicos (furazolidona) causam, freqüentemente reações colaterais, mas continua sendo usado em larga escala (Cortez \& Pankey, 1972). 
Infecções moderadas, especialmente com helmintos causam uma perda diária média de $7 \%$ de proteínas ingeridas. As anormalidades da mucosa jejunal, são provavelmente responsáveis pela má absorção intestinal. Esse aspecto é mais agravante quando se refere as regiões tropicais, em virtude de serem geralmente, menos desenvolvidas e uma grande parte da população infantil apresentar deficit proteico (Giugliano et al., 1978). Outros mecanismos certamente existem interferindo na nutrição do hospedeiro e perda dos nutrientes que são necessários para o próprio metabolismo do parasita. As defesas orgânicas diminuem pacientes portadores de parasitas intestinais. Foi verificado que crianças com helmintíases são mais suceptíveis a infecções bacterianas e viróticas das vias aéreas superiores.

\section{SUMMARY}

A survey was conducted for intestinal parasites of 240 children and adolescents from the city of Nova Olinda do Norte, Amazonas, Brazil. It was found that Ascaris lumbricoides was the most prevalent among the helminths with a percentage of $70,4 \%$ and Giardia lambia among the pathogenic protozoa with $28,4 \%$. Problems of control of parasitic disease in this area, due the lack of education and sanitation, are discussed.

\section{BIBLIOGRAFTA}

AnUírio Estatístico do BrasiL

1976 - Instituto Brasileiro de Geografia e Estatística, Rio de Janeiro.

Blumenthal, D.S. \& Schultz, M.G.

1976 - Effects of Ascaris infection on nutritional status of children. Am. J. Trop. Med. Hyg., $25(5)$ : $682-690$.
Causey, O.R.; Costa, O. \& Causey, C.E.

1947 - Incidência de parasitos intestinais do homem na cidade de Belém, Pará e vizinhanças. Rev. Serv. Esp. Saúde Pública, 1(2) : 221-223.

Cortez, L.M. \& Pankey, G.A.

1972 - Acute pulmonary hypersensitivity due to furazolidona. Am. Rev. Resp Dis., 105: 823-826.

Costa, O.R.

1947 - Incidência de parasitos intestinais em quatro cidades da Amazônia. Rev. Serv. Esp. Saúde Pública, 1(2) : 302-319.

Faust, E.C.; Sawits, W.; Tobie, J.; Odon, V.; Peres, C. \& Lincicome, D.R

1939 - Comparative efficiency of various technics for the diagnosis of protozoa and helminths in feces. J. Parasitol., $25: 241-262$.

Giugliano, R.; Shrimpton, R.; ArKcoll, D.B.; Giugliano, L.G. \& Petrere Jr., M.

1978 - Diagnóstico da Realidade Alimentar e Nutricional do Estado do Amazonas. Acta Amazonica, 8(2) : Suplemento n. 2.

Montoril, M.F.; Ferraroni, J.J. \& Montoril, D.A. 1978 - Diagnóstico Sócio-Parasito-Sanitário da Cidade de Nova Olinda do Norte, Amazonas, Brasil. Acta Amazonica, 8(2) - 91-98.

Ogunba, E.O.

1977 - The prevalence of human intestnial protozoa in Ibadan, Nigeria. J. Trop. Med. Hyg., $80(9)$ : 187-191.

Pinheiro, M.F.S.; Vasconcelos, J.C. \& Wendel, D E. 1976 - Contribuição ao estudo de parasitos intestinais em dois bairros de Manaus, Amazonas. Acta Amazonica, 6(1): 6773 .

(Aceito para publicação em 26/8/79) 